\title{
Sustainability, risks, land use planning: tools for integration
}

\author{
A. Galderisi \& A. S. Profice \\ Department of Urban and Regional Planning, \\ University of Naples Federico II, Italy
}

\begin{abstract}
In the last decades, urban areas have been more and more frequently hit by hazards with catastrophic impacts on human and natural resources. Urban disasters are often characterized as an interactive mix of natural, technological and social events, due to changes of hazards, exposure and vulnerability of territorial systems and to the interactive mix of such changes. These issues are critical both for urban planning and sustainable development, since hazards pose a relevant threat both to the development of cities and to the safeguarding of human and natural resources for the benefit of future generations. Accordingly, the need for integrating both environmental and disaster risk considerations into spatial planning has been largely emphasized. Since the eighties, the role played by environmental issues in land use planning has been consistently growing in all European countries. Nowadays, almost all land use planning processes have to be subjected to a Strategic Environmental Assessment (SEA). On the opposite, Disasters Risk Reduction still represents a marginal goal in land use planning. Risk assessment and prevention is mainly faced through sectoral planning tools, based on a hazard oriented approach and devoting scarce attention to the vulnerability of human and natural resources. Furthermore, risk features as well as the potential impacts of planning policies on such features are often neglected within the SEAs. To face these criticalities, a new tool, the SERA, which could largely contribute to an effective integration of Risk Assessment (RA) into the SEA has been provided. This tool is addressed to support land use planners in evaluating the impact that land use planning choices might have on environmental features of the territory, including risks.

Keywords: urban disasters, risk assessment, sustainable urban planning, complex hazardous events, urban risk mitigation.
\end{abstract}




\section{Unsustainability and new risks in contemporary urban areas}

In 1977, Bateson [1] identified the roots of the ecological crisis in the combined action of "technological advance, population increase and, finally, conventional (but wrong) idea about the nature of man and his relation to the environment". Cities are probably the best example of places where all these roots are embodied. Hence, "whilst cities have always been the engines of human civilization and all the positive, vibrant and productive life that this entails" [2], they currently represent the main challenge for sustainable development.

Numerous scholars have recognised that "cities are causally linked to accelerating global ecological decline and are not by themselves sustainable" [3]. Furthermore, as already underlined in the Brundtland Report [4] and largely remarked by the World Urbanization Prospect [5], "urban areas of the world are expected to absorb all the population growth expected over the next four decades". Therefore cities are currently, and will be probably more in the future, the core of the ecological crisis and, in the meanwhile, the main challenge for steering current development model toward sustainability.

Besides this, according to the German sociologist Beck [6], we live in a "risk society", in which numerous un-wanted side effects - including the ones that affect natural environment and induce or increase hazards and their consequences - are produced together with goods, profits and wealth. Climate change is one of the most macroscopic examples of these effects. According to IPCC [7], by the end of the century sea level will rise and extreme phenomena (storms, droughts, floods, etc.) will become more severe and frequent. Moreover, most of the large cities all around the world are subject to different types of natural hazards, whose frequency and severity could be exacerbated by climate change.

Hence, risks represent a critical issue today which would become more remarkable in the next future: moreover, due to the "emergence of a predominantly urban world" [8], cities would be the core place of risks in the future. Therefore, cities currently represent a major challenge for disasters prevention, since the same features that make them "feasible and desirable their architectural structures, population concentrations, places of assembly and interconnected infrastructure systems - also put them at risk to floods, earthquakes, hurricanes (...)" [9].

Mitchell [10] defined cities as "the crucibles where new kinds of hazard are being fashioned and all ones reshaped, so that the existing ways of dealing with both are thrown into doubts". Moreover, the amount and the variety of elements and systems at stake in urban areas and their vulnerability make the boundaries between natural and technological events blurred, opening the floor to a complex class of events which have been defined in literature as hybrid events [10] or complex hazardous events [11]. Such events more and more often reveal the increasing vulnerability of coupled ecological-human systems and the multidimensional role played by natural environment in recent urban disasters: human modifications on natural environment largely influence the trigger of 
hazards or increase their intensity and effects, whereas hazards themselves may induce consequences on environmental resources which may reverberate on social and economic systems too.

Besides this, the complexity of cities clearly highlights that vulnerability represents a "whole" characterized by numerous dimensions closely interrelated: vulnerability of urban areas to hazards depends, indeed, not only on the physical features of buildings and infrastructures (which is usually the core of the engineering approach to vulnerability analysis), but also on the spatial and organizational features of cities (features of urban fabrics, accessibility, location of strategic and critical facilities, etc.), on the interactions among elements and systems which may influence their capacity to continue functioning in case of hazardous events, on the social, economic and institutional features affecting the capacity of a community to withstand and cope with hazardous events.

Finally, the complex chains of hazards, impacts and damages which characterize recent urban disasters shed lights on the fact that all risk components dynamically change over time and across space: chains of different hazard factors may involve different areas and targets inducing significant cross-scale effects, whilst different aspects of vulnerability arise in different temporal phases after the hazard impact.

Summing up, un-sustainability of cities and features of current urban disasters drive us to focus on the urban scale, embracing the twofold and closely related challenge to drive urban development toward sustainability and to prevent/reduce risks in urban areas. According to Hewitt [12], indeed, "if there could be such a thing as a sustainable development, disaster would represent a major threat to it, or a sign of its failure". To succeed in facing this challenge, a key role has to be assigned to land use planning which, driving its practices toward sustainability and paying more attention to natural equilibriums and dynamics, may largely contribute to risk reduction in urban areas, both in new and existing settlements.

\section{SEA, DRR and land use planning: obstacles towards an integration}

Despite the need for a better integration among sustainable development, risk reduction policies and land use planning has been largely recognised, and although several steps along the path leading to such an integration have been undertaken - also due to the efforts of some international organizations for mainstreaming disaster risk reduction into development processes, and for including risk reduction criteria into environmental regulatory frameworks [1315] - the goal of an effective integration is still far to be achieved both in developing and in developed countries. Italy represents a paradigmatic example of how numerous theoretical, legislative and practical obstacles still interfere with an effective integration among sustainable development, risk reduction policies and land use planning.

Italy is exposed to numerous natural hazards (earthquakes, floods, landslides, volcanic eruptions, coastal erosion, etc.) and more than 1.000 industrial 
hazardous sites are located inside the country, often in natural hazard prone areas. Despite its features, Italy has not yet developed a comprehensive strategy for risk reduction and, apart from some good regional practices, the Italian approach to disasters has been long mainly reactive, in that the regulations in the field of DRR have generally followed disasters. Nevertheless, Italy is only an example of a widespread attitude: in most European countries the "approach to risks is still sectoral and mostly focused on hazards characteristics, rather than being multi-risk and attentive to vulnerability issues" [16]. Moreover, although the need to consider land use planning as a key tool for risk reduction has been widely recognised, the translation of technical hazard and risk assessment into land use planning choices is still hard. According to Greiving et al. [17], in many European countries risk assessment is still a task of sectoral Authorities and the role played by land use planning in risk management, both at regional and local level, is a minor one and is mainly based on information related to hazards, whereas information about the different dimensions of vulnerability is largely missing. Focusing on the Italian experience, it is worth noting that - although at present risk mitigation is one of the main goals of land use planning - risk assessment and the definition of technical measures for risk prevention and mitigation are still in charge of sectoral Authorities. Land use planning tools are required, by some regional planning acts, to provide risk maps, filling up the gaps of sectoral planning in charge of risk assessment and, after 1995, some regional planning acts enlarged regional and provincial competences for risk management, requiring them to identify mitigation measures. Nevertheless, such measures are generally characterized as generic aims in spatial plans both at regional and provincial scale, mainly addressed to prevent future developments in hazardous areas through strict constraints, whereas specific thresholds related to the reduction of damages in existing settlements are not generally defined.

Furthermore, even though risk is increasingly considered as the result of the interaction among hazards, settlements' features, economic and social factors, indepth vulnerability analyses are not very common neither in sectoral nor in land use planning tools.

Nevertheless, one of the main weaknesses is probably related to the fact that DRR policies and land use planning choices up to now are not fully integrated into a single process, resulting from studies, reports, programs developed by different agencies on different geographical scales. The lack of a common strategy is in the meantime the cause and the consequence of the fragmentation of competencies, which depends, in turn, on the legal fragmentation. Moreover, information exchange among different institutions is often difficult and sometimes points out dramatically the lack of shared terminology and techniques [18]. The result of such a situation is the only partial compliance of land use planning tools with norms and obligations or, better, the formal compliance with no attempt to effectively assess the result of land use planning choices on risk features.

In contrast, in the last decades, the key role of sustainability in driving land use planning choices has been largely recognized and, starting from the nineties, sustainable development has become one of the main target of land use planning 
tools, on all geographical scales. Based on the European Directive 42/2001, the Italian Law 153/2005 has forced plans and programs to include the Strategic Environmental Assessment (SEA). Nevertheless, although disasters have been largely recognized as "a serious breakdown in sustainability" [19], most of the SEAs currently developed in Italy are mainly focused on the assessment of the impacts of land use planning choices on the quality of environmental resources (water, soils, air, etc.), often neglecting that environmental alteration may affect risk features, that land use choices may be affected by risk features and, on the opposite, that these choices may influence exposure and vulnerability of communities to hazards or affect hazards themselves.

\section{The SERA procedure}

In 2010, the European Commission has outlined a working paper on "Risk Assessment and Mapping Guidelines for Disaster Management" [20] as a step for establishing, by 2014, a coherent risk management policy, linking threat and risk assessments to decision making. These guidelines represent a significant progress towards an effective multi-risk analysis and emphasize the need for involving stakeholders in risk assessment processes, as well as for extensive public information on the process and outcomes of risk assessments. Nevertheless, no attention has been paid to the potential integration of multi-risk assessment in the framework of the SEA.

Therefore, due to the persisting lack of operative tools for integrating risk assessment into the SEA framework, a procedure aimed at integrating Strategic Environmental Assessment (SEA) and Risk Assessment (RA) has been outlined. The Strategic Environmental and Risk Assessment (SERA) procedure is addressed to guarantee an effective integration of risk reduction issues into land use planning processes, mainly at the Municipal scale, being cities, as mentioned above, the main challenge for steering development processes towards both sustainability and risk reduction.

The procedure largely grounds on the main outcomes arising from three European research projects: the Armonia project, focused on multi-risk assessment addressed to support land use planning choices [21]; the Ensure project, aimed at carrying out an integrated framework for vulnerability assessment [11]; the Enplan project, aimed at defining a common European procedure for the implementation of strategic environmental assessment into planning processes [22].

The main objectives of the SERA can be synthesized as follows:

- the analysis and assessment of environmental features of the territory, including natural hazards;

- the analysis and assessment of the potential interactions among different hazards and/or among hazard and vulnerable targets which may give rise to further hazards;

- the analysis and assessment of vulnerabilities of exposed elements and systems, including natural resources; 
- the assessment of the potential changes to environmental and risk features arising from alternative land use choices;

- the definition of effective prevention and mitigation measures in face both of current environmental and risk features and future ones due to the land use planning choices.

The SERA procedure (Figure 1) is articulated in different phases (green boxes) which follow the ones of the land use planning process (yellow boxes). All phases of the SERA have to be informed to three key topics: "complexity", "sustainability and DRR", "participation". The first one emphasizes the need for looking at cities and risks as complex phenomena. Such an approach requires that, in all phases of land use planning and SERA processes, the multiple interrelationships among the different systems and elements at stake have to be taken into account.

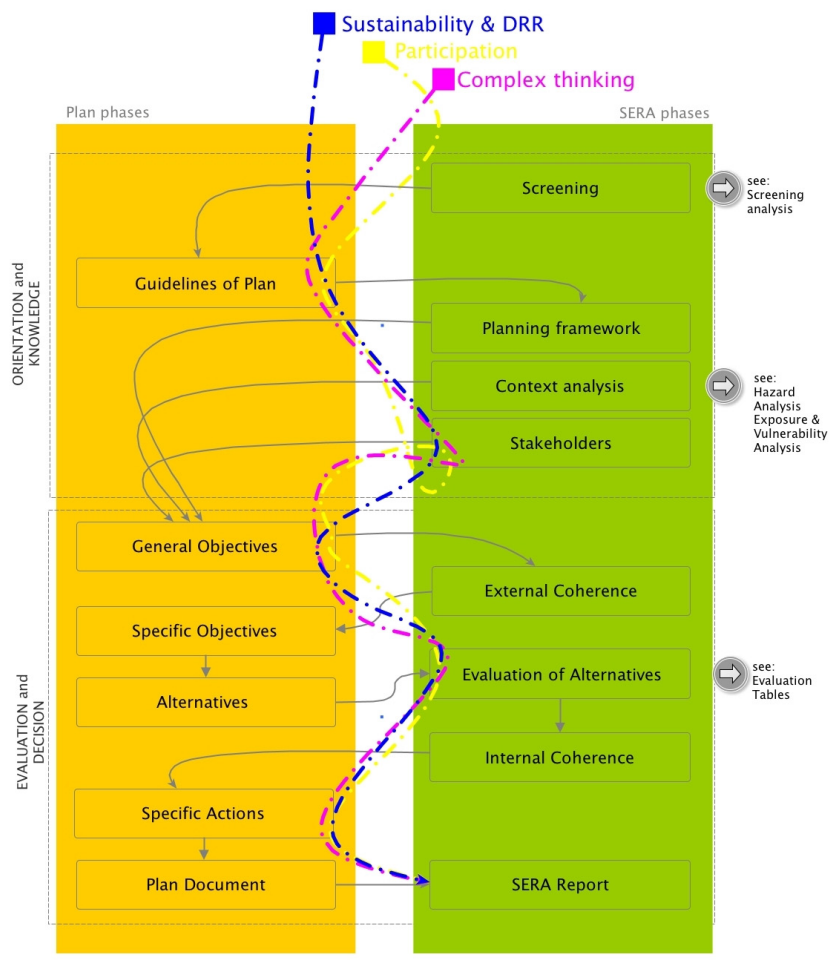

Figure 1: Planning and SERA processes.

The second one emphasizes the need for widening the approach to sustainable development currently pursued by the SEAs, mainly focused on environmental issues, devoting larger attention to the importance that risks might have on all the three constituent parts of sustainable development: environment, social and economic. The third one emphasizes the crucial role of stakeholders and communities both in land use planning and in the SERA process, overcoming the current widespread idea that risk assessment can be interpreted as a technical process. 


\subsection{The orientation and knowledge phase}

According to the ENPLAN guidelines, the starting point of a SEA is the screening analysis, addressed to verify the need for applying SEA. According to the SEA Directive, SEA is not required if the size of the area to be planned is very small or if the plan at stake gives rise to minor modifications to a plan/program already approved and submitted to SEA. To the above mentioned criteria, in the SERA procedure a third one, related to the presence of hazard sources in the planning area, has been added. Such a criterion has a twofold relevance to our aims: first of all, the presence/absence of hazard sources is a key-point for defining if the planning process at stake has to be subjected to the SEA or to the SERA procedure; then, it prevails on the others, in that if the planning tool at stake affects a small area or provides minor modifications to a previous plan, in case the area of concern is a hazard prone one, planning choices might anyway alter the risk features of the area, giving rise to the need for being subjected to SERA. In the Screening Analysis phase, a preliminary hazard assessment is required. Such an assessment can be carried out grounding on existing knowledge (hazard assessment carried out by sectoral Authorities, institutional reports, studies and research developed in respect to the area of concern, etc.) and is addressed to verify if the area at stake is prone to any type of natural and/or technological hazard.

Then, with reference to the Guidelines provided by the Local Authorities in charge of the land use planning process, the second step of the SERA refers to the identification of the legal and/or of the planning framework to which land use planning choices have to refer. In detail, since the SERA has been here sized on a land use planning process aimed at carrying out a Master Plan, all the objectives, constraints and opportunities - mainly in the field of sustainability, environmental protection, risk reduction - arising from National and Regional Laws as well as from general and sectoral land use planning tools on wider geographical scales (Region, Province, etc.) have to be taken into account in this phase.

The following step, the Context Analysis, is addressed to provide an in-depth knowledge-base for guiding land use planning choices; in detail to:

- identify all the key elements (biodiversity, ecosystem consistency, etc.) related to the natural environment and their problems (e.g. pollution, alterations, etc.);

- define the key spatial elements (current land uses, criticalities of network infrastructures, etc.) and the main socio-economical features (unemployment, strengths and weaknesses of the production system, etc.) of the area at stake, including their future trends;

- analyze hazard, exposure and vulnerability features of the area, including their potential changes over time and across space.

Since the first two mentioned sets of analyses are usually included in a SEA, large attention has been paid to the setting up of operative guidelines for a comprehensive multi-risk assessment, taking into account the likely interactions 
among hazard factors and the different facets of vulnerability of the exposed elements and systems.

In respect to hazard assessment, in this phase, all available information related to the different hazard factors have to be systematized and elaborated. Hazard information are generally represented through maps carried out by experts and/or sectoral Authorities that, for each hazard factor, provide a classification of the hazard prone areas into qualitative classes (from low to high or very high). Therefore, starting from the heterogeneous classification of hazard levels generally available in respect to each hazard type, homogeneous hazard classes have to be defined and each partition of the area at stake has to be classified in respect to each hazard, according to these classes. Then, based on the "likely" interactions that may occur among different natural and technological hazard factors [23-25] and through the overlapping of the different hazard maps, areas where potential hazard chains might occur can be singled out.

Exposed elements and systems depend on the type of hazards: thus, for each of the primary and secondary hazard factors previously identified, the main exposed systems and elements have to be singled out. In detail, exposure can be evaluated with respect to type, consistency and importance of elements prone to each hazard. In respect to vulnerability, it is worth reminding that vulnerability of an urban area depends on numerous factors: some of them are related to the features of individual exposed elements (building, natural resources, people, etc.), others are related to the features of urban fabrics (compactness, distribution of critical facilities, etc.), others are related to the social and economic features of the territorial system at stake.

Therefore, all the different facets of vulnerability have to be considered and, at least, physical, functional and socio-economic vulnerability. Whereas the former can be meant as a vulnerability to a stress factor, strictly depending on the type of hazard, functional and socio-economic vulnerability can be interpreted as vulnerabilities to losses, in that they generally arise as a consequence of physical damages [11]. The reduced accessibility to critical facilities due to the damages to road network is a clear example of functional vulnerability, which is due to the close interdependencies among the different elements that constitute an urban system. Socio-economic factors may largely influence the capacity of a community to react to a hazardous event and largely depend on factors such as employment rate, education levels and so on.

In order to assess physical, functional and socio-economic vulnerability of exposed systems and elements different sets of indicators have been defined, based on the above mentioned European research project [11, 21]. It has to be noticed that some of the aspects are significant in respect to one hazard, some in respect to others; hence, the provided indicators have to be adapted and specified in respect to the peculiar hazard features of the area at stake.

Summing up, the suggested steps are addressed to define a picture of the territory in terms of hazard, exposure and vulnerability features, in order to drive and evaluate, in the next phase, land use planning choices. In detail, grounding on the knowledge-base set up in this phase, the impact that land use planning choices might have on the different risk features can be subsequently appraised 
in order to compare and select different planning alternatives and to identify adequate prevention and/or mitigation measures.

The final step of this phase is represented by the identification and involvement of potential stakeholders. Participation is crucial within a SEA and, similarly, within a SERA process. Hence, all relevant institutional and notinstitutional actors (Local Authorities, agencies, no-profit organizations, environmental groups, etc.) have to be identified and effective tools to ensure their involvement both in understanding risk features and in sharing land use planning choices have to be defined. A remarkable issue in this phase is the identification, based on previous exposure and vulnerability assessment, of exposed vulnerable groups, which represent relevant stakeholders to be involved in order to define the risk level they are willing to accept within their territory.

\subsection{The evaluation and decision phase}

In this phase, the SERA procedure is addressed to support the decision making process, driving land use planning choices towards environmental, social and economic sustainability and DRR. The first steps are related to the definition of the General and Specific Objectives of the planning tool at stake. These objectives have to be defined taking into account both objectives and strategies provided by general and sectoral planning tools carried out in respect to the wider geographical areas (Region, Province, etc.) which the Municipal area belongs to, and to the main criticalities arising from the Context Analysis in terms both of environmental and risk features of the area at stake.

Hence, in this phase, planning choices have to be defined: they may be addressed to preserve the existing type and intensity of land use (preservation), or to modify it, changing the intensity and the spatial organization of current land use (requalification) or defining new land uses (transformation).

According to such objectives, the SERA procedure is addressed to guide planners along a path aimed at verifying if preservation or transformation decisions are compatible both with sustainability and DRR goals, grounding on the results of the context analysis in respect both to the features of environmental resources and to the current levels of hazard, exposure and vulnerability.

It is worth noting that the two mentioned goals could be conflicting too. If land use planning decision for a given area is to preserve a current residential use or to increase the residential density, for example, such a choice would be the best one according to sustainability principles, in that it allows us to minimize new land consumption. Nevertheless, the same choice is not necessarily the best one in terms of risk reduction, since the area of concern could be characterized by high levels of hazard, exposure or vulnerability. In these cases, the SERA procedure may drive planners towards the identification of adequate mitigation measures of current risk levels in the area of concern or, even, towards the selection of alternative choices that, anyway, should be addressed to achieve both goals.

In case that land use planning decision is addressed to transform a current land use, foreseeing new settlements in a natural or rural area, such a choice has to be verified not only in respect to sustainability goals but also in respect to 
current multi-hazard levels. Furthermore, since a natural or a rural area is at stake, current vulnerability of natural resources has to be taken into account and - even though the land use planning choice is considered as not compatible measures addressed to reduce existing vulnerabilities have to be suggested (Table 1). Finally, it is worth emphasizing that in the evaluation and decision phase, besides the technical support to the decision making process, participation is largely required: technical decisions have to be discussed and shared with all relevant stakeholders, being crucial, mainly in case of conflicting goals, that priorities of stakeholders and, above all, risk levels that settled communities are willing to accept would be adequately taken into account.

Table 1: An example of evaluation.

\begin{tabular}{|c|c|c|c|c|c|c|}
\hline \multirow{2}{*}{$\begin{array}{l}\text { Goal of the } \\
\text { Master Plan }\end{array}$} & \multirow{2}{*}{$\begin{array}{l}\text { Current } \\
\text { multi-hazard } \\
\text { level }\end{array}$} & \multicolumn{4}{|c|}{ Current vulnerability of natural systems } & \multirow{2}{*}{$\begin{array}{l}\text { Guidelines for } \\
\text { transformation }\end{array}$} \\
\hline & & Very High & High & Medium & Low & \\
\hline \multirow{4}{*}{$\begin{array}{l}\text { Transformation } \\
\text { of (natural or } \\
\text { semi-natural) } \\
\text { open areas }\end{array}$} & Very High & (2) & :2: & (;) & (:) & $\begin{array}{l}\text { Only transformations } \\
\text { that do not entail new } \\
\text { settlements are } \\
\text { allowed; measures } \\
\text { targeted to reduce } \\
\text { vulnerability of natural } \\
\text { resources are } \\
\text { compulsory } \\
\end{array}$ \\
\hline & High & (:) & (2) & (:) & (:) & $\begin{array}{l}\text { Only transformations } \\
\text { that do not entail new } \\
\text { settlements are } \\
\text { allowed; measures } \\
\text { targeted to reduce } \\
\text { vulnerability of natural } \\
\text { resources are advisable }\end{array}$ \\
\hline & Medium & :- & :) & (:) & (:) & $\begin{array}{l}\text { The potential increase } \\
\text { of hazard, exposure } \\
\text { and vulnerability has to } \\
\text { be assessed }\end{array}$ \\
\hline & Low & (:) & (:) & (:) & (;) & No limitations \\
\hline
\end{tabular}

The last phase of the SERA procedure consists of an internal coherence analysis, aimed at verifying the coherence among general, specific objectives and actions within the planning tool, and at carrying out a final report of the whole SERA process.

\section{References}

[1] Bateson, G., Mind and Nature, NJ: Hampton Press, 1977.

[2] Hall, P., Cities in Civilization, Phoenix Giant, 1998.

[3] Rees, W., Wackernagel, M., Urban Ecological Footprints: Why cities cannot be sustainable and why they are a key to sustainability. Environmental Impact Assessment Review, 16, pp. 223-248, 1996. 
[4] WCED, Report of the World Commission on Environment and Development: Our Common Future. www.un-documents.net/wcedocf.htm, 1987.

[5] UN - Department of Economic and Social Affairs, Population Division. World Urbanization Prospects, The 2009 Revision: Highlights. http://esa.un.org/unpd/wup/Documents/WUP 2009_Highlights_Final.pdf, 2010.

[6] Beck, U., The Risk Society: Toward a New Modernization, Frankfurt: Suhrkamp Verlag, 1986.

[7] IPCC, Fourth Assessment Report: Climate Change 2007, NY: United Nation Publishing. www.ipcc.ch/publications and data/ publications and data_reports.shtml, 2007.

[8] Mitchell, J.K., Megacities and natural disasters: a comparative analysis. GeoJournal, 49, pp. 137-142, 1999.

[9] Godschalk, D.R., Urban Hazard Mitigation: Creating Resilient Cities. Natural Hazards Review, 4(3), pp.136-143, 2003.

[10] Mitchell, J.K., Findings and conclusions. Crucibles of Hazard: Mega Cities and Disasters in Transition, ed., J.K., Mitchell, NY: United Nation University, pp. 473-502, 1999.

[11] Ensure EU Project, 7th Framework Programme. www.ensureproject.eu/, 2008-2011.

[12] Hewitt, K., Sustainable Disasters? Perspectives and Powers in the Discourse of Calamity. Power of Development, ed. J. Crush, London: Routledge, pp. 115-128, 1995.

[13] Benson, C., Twigg, J., Tools for Mainstreaming Disaster Risk Reduction: Guidance Notes for Development Organisations. www.unisdr.org/files/ 1066 tools formainstreamingDRR.pdf, 2007.UNEP-ISDR, Environment and Disaster risk. Emerging Perspectives. www.unisdr.org/files/624 Environmentanddisaster riskNov08.pdf, 2008.

[14] UNEP-ISDR, Environment and Disaster risk. Emerging Perspectives. www.unisdr.org/files/624 Environmentanddisaster riskNov08.pdf, 2008.

[15] OECD, Strategic environmental assessment (SEA) and disaster risk reduction (DDR): Revision. Geneva: Dac/Oecd publishing, 2010.

[16] Galderisi, A., Menoni, S., Risk Prevention and Urban Planning. Urbanistica, 134, pp. 20-23, 2007.

[17] Greiving, S., Fleischhauer, M., Wanczura S., Management of Natural Hazards in Europe: The role of Spatial Planning in selected EU Member States. Journal of Environmental Planning and Management, 49(5), pp. 739-757, 2006.

[18] Galderisi, A., Menoni, S., Natural Risk Prevention and Land Use Planning in Italy: Strength and Weaknesses of a System Stretched Between Centralised and Decentralised Authorities. Natural Hazards and Spatial Planning in Europe, eds. M. Fleischhauer, S. Greiving, S. Wanczura, Dortmund: Vertrieb-Dortmund, pp. 97-125, 2006. 
[19] Burby, J.R., Natural Hazards and Land Use: An Introduction. Cooperating with Nature, ed., J.R., Burby, Washington DC: Joseph Henry Press, 1-26, 1998.

[20] EU, Risk Assessment and Mapping Guidelines for Disaster Management. SEC(2010)1626final. http://register.consilium.europa.eu/pdf/en/10/st 17/st17 833.en 10.pdf, 2010.

[21] Armonia EU Project. http://ec.europa.eu/research/environment/ pdf/publications/fp6/natural_hazards/armonia.pdf, 2005-2007.

[22] ENPLAN Interreg III Project. www.interreg-enplan.org/home.htm, 2000-2004.

[23] Steinberg, L. J., Cruz, A. M., When Natural and Technological Disasters Collide: Lessons from the Turkey Earthquake of August 17, 1999. Natural Hazards Review, 5(3), pp. 121-130, 2001.

[24] Schmidt-Thomé P., ed., The Spatial Effects and Management of Natural and Technological Hazards in Europe -ESPON 1.3.1, www.preventionweb.net/files/ 3621_Finalreport.pdf, 2006.

[25] Krausmann, E., Cruz, A. M., Preface. Natural Hazards, 46, pp.139-14, www.springerlink.com/content/56rp422612478216/fulltext.pdf, 2008. 